\title{
Obstetrical and neonatal prognosis of a teenage primiparous pregnancy at the Zafisaona Gabriel Majunga university hospital center
}

\section{Tanjona A. Ratsiatosika ${ }^{1 *}$, Marie Valerie Rajaonarivony ${ }^{1}$, Romuald Randriamahavonjy ${ }^{2}$, Lantonirina Rainibarijaona ${ }^{1}$, Jean Eustache Fanomezantsoa ${ }^{3}$, Martial Rakotonirina ${ }^{3}$, Pierana Gabriel Randaoharison ${ }^{3}$}

\begin{abstract}
${ }^{1}$ Department of Faculty of Medicine, Public Health Department, Antananarivo, Madagascar
${ }^{2}$ Department of Gynecology and Obstetrics in The Soavinandriana Hospital Center of the Faculty of Medicine Antananarivo, Madagascar

${ }^{3}$ Faculty of Medicine of Mahajanga, Zafisaona University Hospital Center Gabriel Mahajanga, Mother-Child Complex, Mahajanga, Madagascar
\end{abstract}

Received: 02 September 2020

Accepted: 07 October 2020

\section{*Correspondence:}

Dr. Tanjona A. Ratsiatosika,

E-mail: ratsiatosika.tanjona@gmail.com

Copyright: () the author(s), publisher and licensee Medip Academy. This is an open-access article distributed under the terms of the Creative Commons Attribution Non-Commercial License, which permits unrestricted non-commercial use, distribution, and reproduction in any medium, provided the original work is properly cited.

\section{ABSTRACT}

Background: Women's fertility is early and high in Madagascar. Through this study, want to know the obstetric and neonatal risks in teenage primiparous pregnancies.

Methods: Carried out a retrospective comparative study of teenage primiparous pregnancies who gave birth beyond 22 weeks of amenorrhea (SA) at the Zafisaona Gabriel Mahajanga university hospital between the period from January 1 to March 31, 2015. The control group is made up of first-time mothers aged 20 to 35 who gave birth in the same center.

Results: The mean age of the patients was $16.77 \pm 1.12$ years. In $43.1 \%$ of cases, the pregnancy was poorly followed. $22.41 \%$ of new-borns to adolescent mothers were hypotrophic at birth. Teenage primiparous pregnancies had a risk of poor pregnancy monitoring compared to their elders (RR: 2.17, 95\% CI [1.35-3.47]) and a risk of giving birth to a low birth weight child (RR: 2.1, 95\% CI [1.05-4.44]). The risk of preeclampsia, death in utero, caesarean section, instrumental extraction was identical between the two groups. Regarding the outcome of newborns, the frequency of premature birth, early neonatal infection, neonatal asphyxia, early neonatal death was not significant.

Conclusions: Apart from fetal hypotrophy, adolescent girls have the same maternal, fetal and neonatal prognosis as their elders.

Keywords: Adolescent, Low weight, Morbidity, Prematurity, Birth

\section{INTRODUCTION}

Madagascar is among the countries where female fertility is high. Note early fertility of $148 \%$ at $15-19$ years and maximum fertility reached from 20-24 years with a rate of $234 \% .^{1}$

According to the world health organization, teenage pregnancy is defined as pregnancy that manifests between 10-19 years of age. ${ }^{2}$ Complications of teenage pregnancy are not yet established. Teenage pregnancy is considered a risky pregnancy for some. ${ }^{3}$ Others consider it a low risk pregnancy. ${ }^{4}$ Faced with this precocious motherhood in Madagascar, it seems urgent to us to identify the risks incurred by Malagasy adolescent parturient. Thus, had conducted a study to answer this question comparing the characteristics of pregnancy and the neonatal outcome of parturient between 10-19 years of age and adult parturient. Only recruited first-time mothers to avoid bias in the results. 


\section{METHODS}

This is a retrospective comparative study that included all teenage primiparous pregnancies aged 10-19 who gave birth after 22 weeks of amenorrhea (SA) at the Zafisaona Gabriel hospital center between the period from January 1 to March 31, 2015.

These adolescents were compared to a control group made up of first-time adults between 20 and 35 years old who gave birth beyond 22 weeks in the same maternity hospital during the same period. The witnesses were drawn at random from the obstetric records.

Studied the following parameters: 1) sociodemographic characteristics- age, level of education and marital status. 2) caracteristics of pregnancy- gestational age, pregnancy follow-up and obstetric complication 3) pronostic of childbirth and neonatal outcome- route of delivery, deaths in utero, neonatal morbidity and mortality (prematurity, respiratory distress syndrome, neonatal infection, admission to intensive care unit, fetal asphyxia by the APGAR score at the fifth minute, fetal weight) and maternal mortality.

\section{Statistical analysis}

Statistical study and data analysis were performed with

Microsoft office excel and CRAN $\mathrm{R}$ software. Percentages were compared using chi square test or
Fisher's exact test. For each test, the value of the degree of significance $\mathrm{p}$ was calculated with a significance level $<0.05$.

\section{RESULTS}

Identified 58 teenage primiparous pregnancies. In the control group, 116 patients were recruited. The ages ranged from 14 to 19 years old. The average age was 16.77 years old. Among them, 31.03\% were single. More than half of these patients had a low level of education. The mean gestational age at the time of delivery was 37.22 years. Regarding pregnancy monitoring, only $43.1 \%$ had regular follow-up recommended by WHO (Table 1).

There were seven cases of preeclampsia and eclampsia. One case of premature rupture of the membrane, one case of retroplacental hematoma and one case of haemorrhagic placenta previa have been reported. In $17.24 \%$ of cases, the patients gave birth prematurely. The frequency of fetal death in utero was $5.17 \%$. Regarding the delivery route, $22.17 \%$ were born by caesarean section and $5.17 \%$ required instrumental extraction (Table 2).

Regarding neonatal outcome, at birth, $17.24 \%$ of newborns were premature, $8.62 \%$ were born asphyxiated, $22.41 \%$ had low birth weight. 12 newborns were admitted to the neonatal intensive care unit. Early neonatal death was found in 3 newborns. Neonatal respiratory distress affected 6 newborns. Neonatal infection was found in $12.06 \%$ of cases (Table 3 ).

Table 1: Maternal characteristics and number of antenatal visits.

\begin{tabular}{|llll|}
\hline Variables & $\mathbf{1 0}-\mathbf{1 9}$ years $(\mathbf{n = 5 8})(\boldsymbol{\%})$ & $\mathbf{2 0 - 3 5}$ years $(\mathbf{n = 1 1 6})(\boldsymbol{\%})$ & P value \\
\hline Mean age \pm ET (years) & $\mathbf{1 6 . 7 7 \pm 1 . 1 2}$ & $\mathbf{2 6 , 0 5 \pm 5 . 2 7}$ & - \\
\hline Single & $18(31.03)$ & $\mathbf{1 2}(10.34)$ & 0.0005 \\
\hline Incomplete secondary & $38(65.51)$ & $30(25.86)$ & 0.00002 \\
\hline CPN $<\mathbf{4}$ & $25(43.1)$ & $23(19.82)$ & 0.0008 \\
\hline Gestational age (SA) (weeks) & $37.22 \pm 3.77$ & $37.61 \pm 3.44$ & - \\
\hline
\end{tabular}

Table 2: Complication of pregnancy and mode of delivery.

\begin{tabular}{|llll|}
\hline Variables & $\mathbf{1 0 - 1 9}$ years $(\mathbf{n = 5 8}) \mathbf{( \% )}$ & $\mathbf{2 0 - 3 5}$ years $(\mathbf{n = 1 1 6})(\boldsymbol{\%})$ & $\mathbf{P}$ value \\
\hline Pre-eclampsia & $7(12.07)$ & $9(\mathbf{7 . 7 6})$ & 0.18 \\
\hline RPM & 1 & 0 & - \\
\hline Placenta previa & 0 & 1 & - \\
\hline HRP & 1 & 1 & - \\
\hline Syphilis & 0 & 0 & - \\
\hline Hepatitis B & 0 & 1 & - \\
\hline Premature delivery & $10(17.24)$ & $20(17.24)$ & 0.49 \\
\hline Mode of delivery & & & 0.2 \\
\hline Instrumental extraction & $3(5.17)$ & $3(2.58)$ & 0.02 \\
\hline Caesarean section & $13(22.41)$ & $42(36.2)$ & 0.006 \\
\hline Low channel & $42(72.41)$ & $61(52.59)$ & \\
\hline
\end{tabular}


Table 3: Neonatal characteristics.

\begin{tabular}{|llll|}
\hline Characteristics & $\mathbf{1 0 - 1 9}$ years $(\mathbf{n}=\mathbf{5 8})(\boldsymbol{\%})$ & $\mathbf{2 0 - 3 5}$ years $(\mathbf{n}=\mathbf{1 1 6})(\boldsymbol{\%})$ & $\mathbf{P}$ value \\
\hline Death in utero & $3(5.17)$ & $\mathbf{5}(4.31)$ & 0.39 \\
\hline Premature birth & $10(17.24)$ & $20(17.24)$ & 0.49 \\
\hline Neonatal asphyxia & $5(8.62)$ & $4(3.44)$ & 0.08 \\
\hline Weight $<\mathbf{2 5 0 0}$ gm & $13(22.41)$ & $12(10.34)$ & 0.02 \\
\hline Early neonatal death & $3(5.17)$ & $4(3.44)$ & 0.29 \\
\hline Respiratory distress & $6(10.34)$ & $7(6.03)$ & 0.16 \\
\hline Mater-fetal infection & $7(12.06)$ & $7(6.03)$ & - \\
\hline
\end{tabular}

Comparing with the controls, the adolescents have a poor follow-up of pregnancy OR: $2.17(1.35-3.47) \mathrm{p}=0.0008$, with a risk twice as high. On the other hand, the risk of preeclampsia, prematurity, fetal death in utero, premature rupture of the membrane, instrumental extraction and caesarean section was identical between the two groups (Table 4). The risk of low birth weight was twice as high in adolescent girls. There is no significant difference in the occurrence of neonatal asphyxia, respiratory distress, early neonatal death, and neonatal infection (Table 5).

Table 4: Obstetrical risk.

\begin{tabular}{|lll|}
\hline Variables & RR & IC 95\% \\
\hline CPN <4 & 2.17 & $1.35-3.47$ \\
\hline Preeclampsia & 1.55 & $0.61-3.96$ \\
\hline Natural delivery & 1.37 & $1.08-1.74$ \\
\hline Caesarean & 0.61 & $0.36-1.05$ \\
\hline Instrumental extraction & 2 & $0.41-9.6$ \\
\hline Death in utero & 1.2 & $0.29-4.84$ \\
\hline
\end{tabular}

Table 5: Neonatal risk.

\begin{tabular}{|lll|}
\hline Variables & RR & IC 95\% \\
\hline Neonatal asphyxia & 2.5 & $0.69-8.95$ \\
\hline Weight $<\mathbf{2 5 0 0}$ gm & 2.1 & $1.05-4.44$ \\
\hline Neonatal respiratory distress & 1.71 & $0.60-4.86$ \\
\hline Neonatal infection & 2 & $0.73-5.43$ \\
\hline Early neonatal death & 1.5 & $0.34-6.48$ \\
\hline
\end{tabular}

\section{DISCUSSION}

To the knowledge, there is no study that has evaluated the outcome of teenage pregnancy in Madagascar. This study is the first. Two salient facts were found in this study: poor prenatal follow-up and the high incidence of low birth weight infants in teenage girls. The obstetric and neonatal outcome was identical between the two groups. Although adolescence is considered a risk factor for progression to pathological pregnancy, did not find this result. However, our study has its limitations. This is a single-center, retrospective study and were unable to analyse the number of gestational diabetes, the existence of overweight, smoking in teenage girls. Patients with risk factors did not benefit from routine screening for gestational diabetes.
The occurrence of teenage pregnancy is a common situation in Madagascar. The proportions of adolescent girls who have started fertile life increase rapidly with age, from $8 \%$ at age 15 to $57 \%$ at age 19 , the age at which $50 \%$ of girls have already had at least one child. The percentage of adolescent girls who have already started their fertile life is significantly higher in rural areas $(35 \%)$ than in urban areas $(17 \%) .{ }^{1}$ Through this study, found that $65 \%$ of these adolescent girls are illiterate and/or adolescents who drop out of school early. A national survey in Madagascar found that fertile life decreases dramatically with increasing educational attainment from $60 \%$ among the uneducated to $16 \%$ among those with secondary school or above. ${ }^{1}$ Randriambololona found the same result in a hospital center in the capital. The peak of educational attainment was secondary. ${ }^{5}$ Result is identical to a study carried out in Congo, Latin America and the United Kingdom. ${ }^{6-8}$ According to the WHO, education in itself is a major protective factor against teenage pregnancies: the longer go to school, the fewer teenage pregnancies. ${ }^{2}$

In addition, $31 \%$ were single mothers. African teenage mothers are most often single mothers. ${ }^{5,6}$ Even in developed countries the result is similar. ${ }^{9}$ These patients have an unfavorable socio-economic profile. They live in a precarious context.

One of the major findings of this study is the poor monitoring of pregnancy in this group of parturient. In fact, they are twice as likely to have poor pregnancy monitoring OR: 2.17 (1.35-3.47) $\mathrm{p}=0.0008$ (Table 4). Explanations can be provided. This is linked to a delay in reporting pregnancy. Often these are teenage girls in school. Pregnancy is often denied until an increase in the size of the uterus or active fetal movements are perceived. These adolescent girls have a difficult socioeconomic condition. The performance of prenatal checkups and ultrasound for pregnancy monitoring are not performed correctly. A recent multicenter study showed that in low-income countries, adolescent girls have fewer antenatal visits $(<4)$ compared to their elders. ${ }^{10}$ In French Guiana, the finding is similar. There were fewer than four prenatal follow-ups in adolescents. ${ }^{11}$ In Cameroon, there was no significant difference between the two groups. ${ }^{12}$ The provision of adequate prenatal care has been shown to provide some protection against fetal and infant mortality in this population. ${ }^{13}$ 
In this study, $12 \%$ of teenage pregnancies were complicated by preeclampsia. They had the same risk as their elders. This rate is identical to that of Rasheed and Congote et al. ${ }^{13-15}$ On the other hand, in European countries, this rate is around $3-4 \% .^{4,7,16}$ The occurrence of preeclampsia in adolescent girls is contradictory. ${ }^{17}$ The study is identical to studies carried out in Latin America and England. There was no significant difference. ${ }^{7,8}$ For some studies, teenage pregnancy constitutes a higher risk factor for preeclampsia. ${ }^{18}$ Anatomical, biological and physiological immaturity has been suggested. ${ }^{14}$ For others, they have found a protective effect against the occurrence of hypertension during pregnancy. ${ }^{15,19}$ Thus, offer more appropriate care in this population group. Information should be given to adolescent girls in school. National education programs should include pregnancy monitoring to provide these adolescent girls with the information they need to prepare for future pregnancy.

Regarding the delivery route, the number of caesarean sections was lower in adolescent girls. In $22 \%$ of cases, adolescent girls underwent caesarean section. This rate is identical to that of Yuce. ${ }^{4}$ There was no significant difference between the two groups. The result is identical to that of Alouini in France and Iloki in Congo and Cameroon. ${ }^{6,12,20}$ Contrary to popular belief, that they had an imperfect pelvis, poorly developed, with a risk of mechanical obstructions, adolescent girls were in favor of a vaginal birth For others, pregnancy in young adolescents is a protective factor for caesarean section. ${ }^{7,15,16,21}$ A study in Latin America on 854,377 adolescent girls showed that teenage pregnancy is a protective factor in caesarean section. ${ }^{8}$

A multicenter study showed that caesarean section secondary to fetal-pelvic disproportion mainly concerned adolescents under 15 years of age. On the other hand, after 16 years, there is a protective effect. ${ }^{10}$ Hamada in Morocco did not find a significant difference in the rate of caesarean sections among adolescents. In contrast, the number of indications for mechanical obstructed labor was higher. ${ }^{22}$ Indeed, in the study, adolescent girls often have a low fetus which would favor vaginal birth. The limitation in our study is the lack of caesarean section rates for foetopelvic disproportion. The number of adolescent girls under 15 has not been separated from other adolescent girls.

Instrumental extraction involved $5.17 \%$ of patients. There was no significant difference between the two groups. In the literature, adolescent girls have the same risk of instrumental extraction as their elders. ${ }^{12,15}$ Even young adolescent girls under 15 had the same risk of instrumental extraction as those aged 16-19. ${ }^{23}$ A study conducted in Morocco had shown a higher rate of instrumental extraction in adolescent girls. (37.32\%, $\mathrm{p}=0.02)^{22}$

Had $17.24 \%$ preterm delivery. This rate is higher than that reported by Randriambololona. This difference is explained by the absence of neonatal resuscitation in this center. The result is very high compared to other African countries. In Congo, Morocco and Egypt, this rate was 6.8, 4.7 and $13.2 \%$ respectively among adolescent girls. $^{6,14,22}$ Condeagudelo and Hamada et al did not find a difference between the two groups. ${ }^{8,22}$ Alouini in a study in Loiret found a higher risk of prematurity in mothers of teenage mothers. $(8.82 \mathrm{Vs} 5.39 \% \mathrm{p}=0.05) .{ }^{20}$

The number of in utero deaths was identical between the two groups. $5.17 \%$ of the foetuses died in utero. This rate is higher compared to a study carried out in Egypt and Congo (4.3\%). ${ }^{6,14}$ In developed countries, this rate is only $0.8 \%{ }^{7}$ While the relationship between death in utero and advanced maternal age is established, data on adolescent girls remains contradictory. In our study, adolescent girls have the same risk of dying in utero as their elders. Dowle reported the same result. ${ }^{7} \mathrm{~A}$ meta-analysis for patients under 20 years of age did not find a significant difference in death in utero (RR: $1.31 ; 95 \% 0.80-2.13$ ). ${ }^{24}$ A Colombian study even found that adolescent girls developed a lower risk of intra-uterine fetal death. ${ }^{15}$

Iloki found a higher rate among teenage girls. ${ }^{6}$ Adolescent girls under 15 are most at risk. Salihu and Wilson et al. reported relative risks of 1.57 (95\% CI, 1.47-169) and 2.6 (95\% CI, 2.1-3.3) respectively of MFIU for this very young population compared to a group of referrals of patients aged 20-24. ${ }^{25,26}$

Although the rate of APGAR of less than seven in the fifth minute is twice as high among adolescent girls, this difference is not significant. Many studies had similar results. ${ }^{7,8,14,20,22}$ In this study, were unable to analyse the fetal acid-base balance at birth. Which constitues one of the limits of this study.

In $22.41 \%$ of cases, newborns born to teenage mothers had low birth weight. This risk is twice as high in this population (OR: $2.1(1.05-4) \mathrm{p}=0.02)$. Congolese and Cameroonian studies have found the same risk in adolescent girls. ${ }^{12,27}$ In addition, a study conducted in Latin America found that adolescent girls have a risk of neonatal hypotrophy regardless of their age group. ${ }^{8}$ Several studies attribute this risk of low birth weight to factors that may be associated with young maternal age: anaemia, maternal physical condition, premature delivery, pathologies associated with pregnancy, insufficient maternal weight gain, maternal nutritional status and the quality of pregnancy monitoring. ${ }^{22}$ However, the results remain discordant, Dowle, Soula and Ergen et al did not find a significant difference in teenage primiparous pregnancies regardless of the age group age. ${ }^{7,11,16}$

Of these newborns, $20.68 \%$ were admitted to neonatal intensive care. This rate is similar to that of Ngowa $(16.14 \%)$ and Soula et al $(25 \%)$ but greatly exceeds that of Hamada et al $(1.28 \%) .{ }^{11,12,22}$ In Congo, this rate was 
$62.8 \% .^{28}$ the result is similar to the literature which found no significant difference between the two groups. ${ }^{20,22}$

Early neonatal death is similar between the two groups. $5.17 \%$ died in the early neonatal period. In Africa, perinatal death is around $5-7 \%$ in adolescent girls. ${ }^{10}$ The result is similar to the literature which found no significant difference between the two groups..$^{8,12,20,22}$ The occurrence of neonatal infection was $6.03 \%$. This rate is lower compared to a study in Loiret, France (14.70\%). ${ }^{20}$ This study also found no significant difference when comparing teenage girls to their elders. This similar risk between the two groups in this study may be explained by the lack of regular follow-up during antenatal visits. There is no routine vaginal sampling during pregnancy. Urine test strips for infection are not done regularly. This situation is the same for adolescent girls as well as for their elders.

Regarding respiratory distress at birth, six newborns presented respiratory abnormalities at birth. This rate is $6.03 \%$ among their elders. This rate is not different between the two groups. Congote-Arango et al had found $1.1 \%$ hyaline membrane disease at birth and this rate is identical between the two groups. ${ }^{15}$

\section{Limitations}

This study is a retrospective, single-center urban study. The frequency of gestational diabetes, the psychological impact, long-term follow-up, contraception and the frequency of anaemia have not been evaluated due to lack of information.

\section{CONCLUSION}

Through this study, were able to observe that teenage pregnancy was at risk of poor prenatal care and neonatal hypotrophy. Can improve the prognosis of these teenagers by offering a regular medical visit. In contrast, neonatal morbidity and mortality was identical between the two groups. The route of delivery was also the same. This study is the first carried out in Madagascar. A largescale multicenter study would be necessary to provide more information on the prognosis of the pregnancy of these adolescent girls in order to reduce the rate of maternal-fetal morbidity and mortality, which remains very high in Madagascar.

\section{Funding: No funding sources}

Conflict of interest: None declared

Ethical approval: The study was approved by the Institutional Ethics Committee

\section{REFERENCES}

1. National Institute of Statistics (Instat) and ICF Macro. Madagascar Demographic and Health Survey 2008-2009. Antananarivo, Madagascar: Instat and ICF Macro 2010.
2. WHO. Early marriages, adolescent and young pregnancies. Report by the Secretariat. A 65/13. Geneva, Switzerland: WHO. 2012.

3. Jancky E, Gallais A, Landre M. General information on teenage pregnancy and childbirth. Encycl Med Chir Gyn Obst. 1996;016-D-10:6.

4. Yuce T, Aker SS, Seval MM, Kalafat E, Soylemez F. Obstetric and neonatal outcomes of adolescent pregnancy. North Clin Istanbul. 2015;2(2):122.

5. Randriambololona D, Raobelle AE, Rafehivola HI, Rajaonarison B, Hery HR. Profile and characteristics of pregnant adolescents in Madagascar. Med Sante Trop. 2014;24:217-8.

6. Iloki LH, Koubaka R, Itoua C, Mbemba Moutounou GM. Teenage pregnancy and childbirth in Congo. $\mathbf{J}$ Gynecol Obstet Biol Reprod. 2004;33:37-42.

7. Marvin-Dowle K, Kilner K, Burley VJ, Hora S. Impact of adolescent age on maternal and neonatal outcomes in the Born in Bradford cohort. BMJ. 2018;8:1-9:e016258.

8. Conde-Agudelo A, Belizan JM, Lammers C. Maternal-perinatal morbidity and mortality associated with adolescent pregnancy in Latin America: Cross-sectional study. Am J obstet Gynecol. 2005;192:342-9.

9. Debras K, Revaux A, Bricou A, Laas E, Tigaizin A, Benbara A et al. Becoming obstetrician and neonatal in teenage pregnancies: cohort of patients in SeineSaint-Denis. Obstet Fertility Gyneecol. 2014:1-6.

10. Ganchimeg T, Mori R, Ota E, Koyanagi A, Gilmour, S, Shibuya K. Maternal and perinatal outcomes among nulliparous adolescents in low- and middleincome countries: a multi-country study. BJOG. 2013; 120:1622-30.

11. Soula O, Carles G, Largeaud M, El Guindi W, Montoya Y. Pregnancies and childbirth in adolescents under 15 years. Study of 181 cases in French Guiana. J Gynecol Obstet Biol Reprod. 2006;35:53-61.

12. Ngowa JDK, Kasia JM, Pisoh WD, Ngassam A, Noa C. Obstetrical and Perinatal Outcomes of Adolescent Pregnancies in Cameroon: A Retrospective Cohort Study at the Yaoundé General Hospital. Open J Obstet Gynecol. 2015;5:88-93.

13. Malabarey OT, Balayla J, Klam SL, Shrim A, Abenhaim HA. Pregnancies in young adolescent mothers: a population-based study on 37 million births. J Pediatr Adolesc Gynecol. 2012;25:98-102.

14. Rasheed S, Abdelmonem A, Amin M. Adolescent pregnancy in Upper Egypt. Int $\mathbf{J}$ Gynecol obstet. 2011;112:21-4.

15. Congote-Arango LM, Vélez-Garcia MA, RestrepoOrrego L, Cubides-Munevar A, Cifuentes-Borrero R. Adolescencia como factor de riesgo para complicaciones maternas y perinatales en cali, colombia, 2002-2007. Cross-sectional studio. Rev Colomb Obstet Ginecol. 2012;63:119-26.

16. Ergen EB, Yayla CA, Kilicci C, Sanverdi I, Kocakusak CK. Maternal-fetal outcome associated with adolescent pregnancy in a tertiary referral 
center: a cross-sectional study. Ginekologia Polska. 2017;88(12):674-8.

17. Fleming N, O'Driscoll T, Becker G, Spitzer RF. Adolescent Pregnancy Clinical Practice Guideline. J Obstet Gynaecol Can. 2016;38(12):704-23.

18. Kongnyuy EJ, Nana PN, Fomulu N, Wiysonge SC, Kouam L, Doh AS. Adverse perinatal outcomes of adolescent pregnancies in Cameroon. Matern Child Health J. 2008;12(2):149-54.

19. Fleming N, Ng N, Osborne C, Biederman S, Yasseen 3rd AS, Dy J et al. Adolescent pregnancy outcomes in the province of Ontario: a cohort study. J Obstet Gynaecol Can. 2013;35:23-45.

20. Alouini S, Randriambololona R, Randriamboavonjy R. Risk factors for pregnancy, childbirth and postpartum in adolescent girls in the Loiret department. J Gynecol Obstet Biol Reprod. 2015;44:443-50.

21. Harrison K, Rossiter C, Chong H. Relations between maternal height, fetal birthweight and cephalopelvic disproportion suggest that young Nigerian primigravidae grow during pregnancy. BJOG. 1985;92:40-8.

22. Hamada H, Zaki A, Nejjar H, Filali A, Chraibi C, Bezad R et al. Adolescent Pregnancy and Childbirth: Characteristics and Profile About 311 cases. J Gynecol Obstet Biol Reprod. 2004;33:607-14.

23. Wemaux-Denis C, Garabedian C, Huc A, Cailleret O, Depoortere MH, Hammou Y. Adolescent pregnancy and childbirth: is the obstetric prognosis more unfavorable between 13 and 15 years? Obstet Gyneecol Fertility Senol. 2017;45:5-8.
24. Flenady V, Koopmans L, Middleton P, Frøen JF, Smith GC, Gibbons K et al. Major risk factors for stillbirth in highincome countries: a systematic review and meta-analysis. Lancet. 2011;377:133140.

25. Salihu HM, Sharma PP, Ekundayo OJ, Kristensen S, Badewa AP, Kirby RS et al. Childhood pregnancy (10-14 years old) and risk of stillbirth in singletons and twins. J Pediatr. 2006;148:522-6.

26. Wilson RE, Alio AP, Kirby RS, Salihu HM. Young maternal age and risk of intrapartum stillbirth. Arch Gynecol Obstet. 2008 278:231-6.

27. Luhete PK, Mukuku O, Tambwe AM, Kayamba PKM. Study of maternal and perinatal prognosis during childbirth in adolescents in Lubumbashi, Democratic Republic of Congo. PAMJ. 2017;26:182.

28. Mayanda HF, Malonga H, Djonob S. Newborns to adolescent mothers in Congo. Rev Pediatr. 1990;9:307-4.

Cite this article as: Ratsiatosika TA, Rajaonarivony MV, Randriamahavonjy R, Rainibarijaona L, Fanomezantsoa JE, Rakotonirina M, et al. Obstetrical and neonatal prognosis of a teenage primiparous pregnancies at the Zafisaona Gabriel Majunga university hospital center. Int J Reprod Contracept Obstet Gynecol 2020;9:4806-11. 